\title{
ASH115M2 MACHINE FOR ELECTROSLAG WELDING OF VERTICAL, INCLINED AND CURVILINEAR BUTT JOINTS
}

\author{
G.V. ZHUK ${ }^{1}$, A.V. SEMENENKO ${ }^{1}$, I.I. LYCHKO ${ }^{2}$, S.M. KOZULIN ${ }^{2}$ and Anat.V. STEPAKHNO ${ }^{3}$ \\ ${ }^{1} \mathrm{SC}$ «EDTB of the E.O. Paton Electric Welding Institute of the NAS of Ukraine» \\ 15 Kazimir Malevich Str., Kiev, Ukraine. E-mail: dktbpaton@gmail.com \\ ${ }^{2}$ E.O. Paton Electric Welding Institute, NASU \\ 11 Kazimir Malevich Str., 03680, Kiev, Ukraine. E-mail: office@paton.kiev.ua
}

\begin{abstract}
Design features of a modern machine for electroslag welding of vertical, inclined and curvilinear butt joints are described. It enables manufacturing unique metal-intensive items. 5 Ref., 2 Figures.
\end{abstract}

Ke y words : electroslag welding, vertical and curvilinear joints, control system, travel mechanism, guide rail, drive carriages

In May, 2016 specialists of SC «EDTB of the E.O. Paton Electric Welding Institute of the NAS of Ukraine» [1] and PJSC «PPWE of the E.O. Paton Electric Welding Institute of the NAS of Ukraine» (Kiev) [2] introduced two electroslag welding machines ASh115M2 in a metallurgical enterprise (Figures 1,2).

At this moment electroslag welding is not as common, as, for instance, submerged-arc or gas-shielded welding.

It is applied in manufacture of unique metal-intensive items, which are not mass-produced. Leading foreign manufacturers of welding equipment do not offer electroslag welding equipment in their catalogs, so that it is difficult to say, whether they are manufacturing such equipment. There are no manufacturers of modern electroslag equipment in the CIS territory. Only such wellknown apparatuses as A-535 and AD-381 are proposed.
New ASh115M2 machines are designed for electroslag welding of vertical, inclined and curvilinear butt joints with curvature radius $R>4000 \mathrm{~mm}$ and angle of inclination of $\pm 25^{\circ}$ from the horizontal, as well as butt joints of sheet structures with one-sided forced formation of the weld.

Ash115M2 machine includes:

- electroslag unit with control panel - 1 pc;

- guide rail with supports - 1 set;

- frame with spool for electrode wire -2 pcs;

- control panel - 1 pc;

- welding current source -2 pcs.

Electroslag unit with control panel is a mounting self-propelled heavy-type apparatus, fitted with all the required mechanical and electromechanical correctors, as well as sensors for making high-quality welds. It is designed so that it could be disassembled

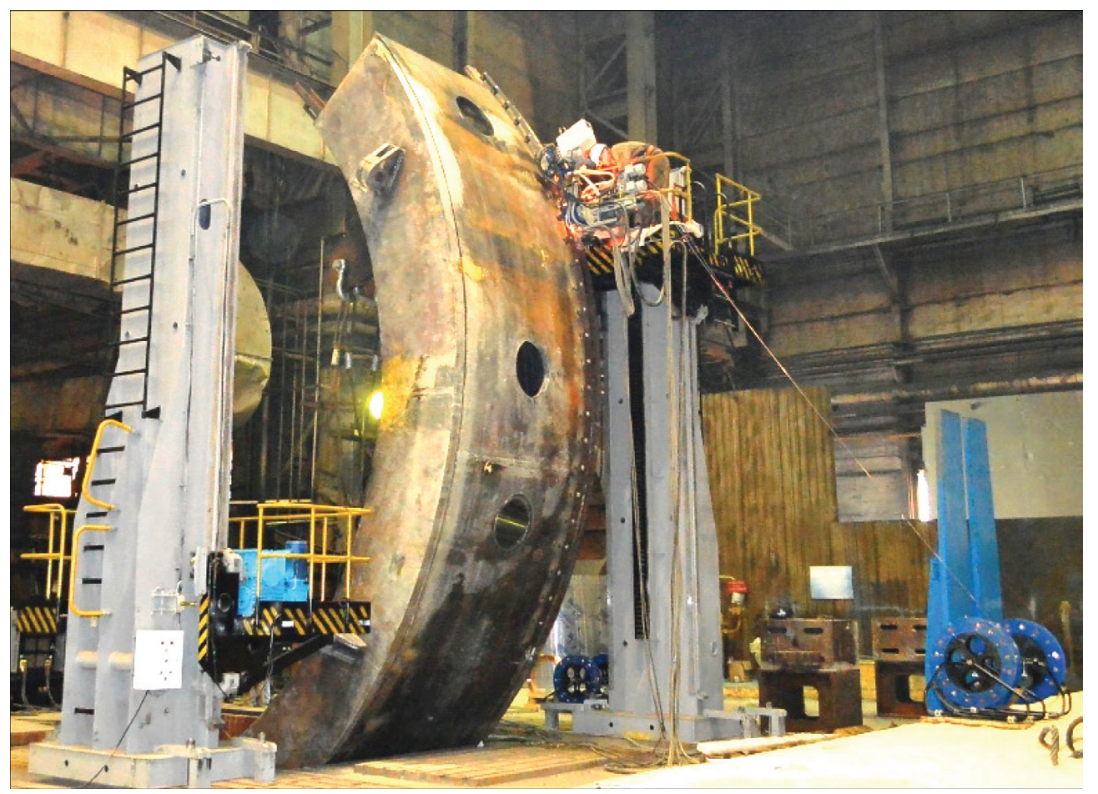

Figure 1. Welding of converter support half-ring 
into four main components, which can be easily and quickly put together. These are travel mechanism, suspension, oscillator and control panel.

Travel mechanism is fitted with special pressdown rollers (they also act as wheels for the drive carriage), which allow fastening and removing it in any part of the guide rail without disassembling the unit. Such a design greatly facilitates for welders fastening the unit on the guide rail in site and its removal after completion of operations. Previously, in all the units the drive carriages were fastened and removed from the start or end of the guide rail. This increased the time of unit mounting and created a lot of inconvenience for the operator.

Owing to a new mechanism of rotation, the unit enables making position circumferential butt joints, during which process the welding operator changes the spatial position of the nozzles.

The guide rail is a flexible strip of spring steel with involute rack at the end face. It consists of several parts, abutted to each other (length is determined by the length of the future weld). The rail is fastened on supports which are welded to the item by erection welds.

Frames with electrode wire spool (two pieces) are placed separately near the unit. To avoid sharp inflections of wire conduits when making extended welds, it is necessary to envisage a lifting platform for lifting the spools with welding wire and the welding operator.

SU331 system was developed to control the technological process of electroslag welding of items, which provides control of all the machine mechanisms and the two welding sources VDU-1202P.

SU331 system is based on programmable controller of CJIM type of Omron (Japan). Modern frequency inverters of Omron V1000 type are applied to control asynchronous electric motors of the unit.

\section{Specification of ASh115M2 machine}

Welded item thickness, $\mathrm{mm}$. . . . . . . . . . . . 80-200

Electrode wire diameter, $\mathrm{mm} \ldots \ldots \ldots \ldots \ldots \ldots \ldots \ldots$

Number of electrode wires, pcs $\ldots \ldots \ldots \ldots \ldots \ldots \ldots 2$

Electrode wire feed rate, not more than, $\mathrm{m} / \mathrm{h} \ldots \ldots \ldots 250$

Rated welding current per one electrode

(at $100 \%$ duty cycle), A . . . . . . . . . . . . . . . . . 1000

Rated voltage and frequency of the mains . . . $380 \mathrm{~V}, 50 \mathrm{~Hz}$

Travel speed, not more than, $\mathrm{m} / \mathrm{h} \ldots \ldots \ldots \ldots \ldots \ldots \ldots 10$

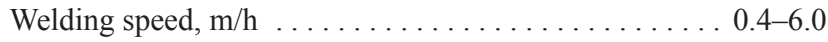

Transverse oscillation speed, $\mathrm{m} / \mathrm{h} \ldots \ldots \ldots \ldots \ldots$. 20 . . . . .

Nozzle dwell time at pool edge, $\mathrm{s} \ldots \ldots \ldots \ldots \ldots$. . . . . . . . . . .

Adjustable electrode spacing, $\mathrm{mm}$. . . . . . . . . . 50 50-150

Oscillation range, not more than, $\mathrm{mm} \ldots \ldots \ldots \ldots \ldots$

Ranges of adjustment of electrode «dry»

extension, $\mathrm{mm}$. ................... 40-120

Ranges of adjustment of angles of electrode

inclination to slag pool surface $\ldots \ldots \ldots \ldots \ldots \ldots 25^{\circ}$

Flow rate of water (shop line) for shoe cooling, $1 / \mathrm{min} \ldots \ldots 25$

Correction of nozzles across the gap, $\mathrm{mm} \mathrm{\ldots ... \ldots \ldots .. \pm 20}$

Transverse correction of the shoe, $\mathrm{mm} \ldots \ldots \ldots \ldots \ldots \pm 25$

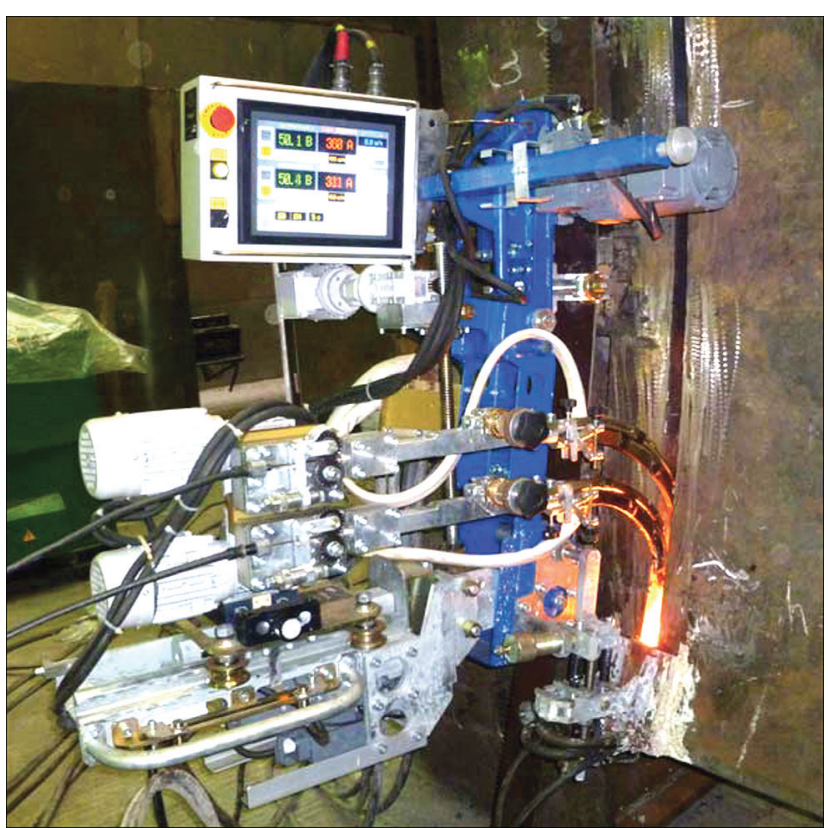

Figure 2. Appearance of ASh115M2 unit

During control system development, special attention was given to ergonomics and operator comfort.

Convenient control panel with colour sensor display of Omron NS12 type allows the operator monitoring and setting the welding parameters, as well as controlling the operation of machine mechanisms. Technological and emergency messages are displayed in addition to displaying the digital instruments, controls and sensors.

Welding rectifiers VDU-1202P produced by PJSC «PPWE of the E.O. Paton Electric Welding Institute» were included into the machine set as welding current sources.

Many years of development of similar apparatuses by designers of SC «EDTB of the E.O. Paton Electric Welding Institute of the NAS of Ukraine» were taken into account during design work performance*, and modern components from leading world manufacturers were applied [3-5]. In view of that, we can state that Ash115M2 machine has incorporated all the best elements that are now offered by electroslag welding and welding equipment.

"A.K. Polishchuk, M.I. Dubovoj, V.D. Kovalev, P.A. Panukhnik and M.A. Strelnikov took part in the work.

1. www.oktb-paton.org.ua

2. $w w w$.paton.ua

3. (1980) Electroslag welding and surfacing. Ed. by E.O. Paton. Moscow: Mashinostroenie.

4. Paton, B.E., Dudko, D.A., Yushchenko, K.A. et al. (1987) Electroslag welding. Results, problems and prospects of development. Avtomatich. Svarka, 5, 32-42.

5. Yushchenko, K.A., Lychko, I.I., Sushchuk-Slyusarenko, I.I. (1999) Effective techniques of electroslag welding and prospects for their application in welding production. Welding and Surfacing Rev., Vol. 12, 108

Received 26.09.2016 